\title{
E-Commerce and e-Government: How Do They Compare? What Can They Learn From Each Other?
}

\author{
Hans J (Jochen) Scholl, Karine Barzilai-Nahon, Jin-Hyuk Ahn, Olga H Popova, and Barbara Re \\ The Information School, University of Washington, University of Camerino/Italy \\ \{jscholl,karineb,jinhyuk,opopova\}@u.washington.edu,barbara.re@unicam.it
}

\begin{abstract}
For more than a decade e-Commerce and eGovernment applications have made major impacts in their respective sectors, private and public. Some time ago, we presented early insights from a comparative study of the two phenomena. This paper reports on more robust findings from an ongoing empirical investigation and deepens our understanding of similarities and differences between e-Commerce and e-Government. The findings show that despite major similarities the two phenomena follow quite separate and distinct trajectories.
\end{abstract}

\section{Introduction}

According to preliminary results from our earlier study, e-Commerce and e-Government have different drivers, priorities, and governing principles. While private-sector CIOs mainly target e-Commerce applications at process simplification, service quality enhancements as well as cost and labor savings, their public-sector counterparts see e-Government applications as instruments for establishing an information technology (IT) architecture, fostering cultural change, and hiring/retaining expert labor [36].

Our pilot study further found that illuminating similarities and differences exist in (1) information management regarding the management of content, which was perceived as a major challenge. Also, the sheer volume of information, old and new, as well as accuracy and timeliness of information it was said required new presentation formats, exchange strategies, and operations in both sectors. Furthermore, ease of use and usability were prominent foci in both e-Commerce and eGovernment. Some differences were detected in areas such as electronic record keeping, where the public sector emphasized the legal liability issue as a main concern and driver, whereas the private sector focused on the technical issues. In (2) process management, although the transaction volumes in e-Commerce were found far higher than in e-Government, in e-Government online transactions play an increasingly important role. Differences were found in the extent and sophistication of process redesign between the sectors. E-Commerce redesigns were found far more advanced than those in eGovernment. Further, while speed of transaction was found an essential element of e-Commerce, less emphasis was put on this aspect in e-Government.
In the context of (3) stakeholder relations, the balancing of stakeholders' interests and managing their expectations was found similar in both e-Commerce and e-Government. However, the public decision-making process required more emphasis and effort in this regard. Stakeholders in e-Commerce preferred network approaches, while governments had preference for alliances to include every important stakeholder.

In (4) customer/citizen focus, we had seen evidence for a difference in drivers. While the expansion of eCommerce was overwhelmingly driven by the profit and excellent customer service motivation, e-Government initiatives were driven by the motivation to serve citizens and to involve and let them participate. In addition, in eGovernment we also noticed a commitment to ethics in service to citizens, for which we found no equivalent in eCommerce.

Finally, the (5) digital divide with respect to equal access, literacy, reach, language, content, and infrastructure was a major concern in e-Government practice. E-Commerce practice was much less concerned with the digital divide, where it mainly expanded to reaching potential customers and providing them secure and safe transactional spaces.

This paper expands and qualifies the findings of our earlier study. Interestingly, all preliminary findings hold in light of a much-expanded base of data points. Our second round of empirical research on the subject surfaced a number of new insights regarding the evolutionary paths and emphases of e-Commerce and eGovernment. We are confident that the expanded understanding of the complex mesh of technological, organizational, and social factors and processes involved in e-Commerce and e-Government will lead to practicerelevant cross-fertilization and reduction of unnecessary reduplication.

This paper is organized as follows. First, we briefly update the pertinent literature on e-Commerce and eGovernment. Second, we introduce and discuss the study design followed by the presentation and discussion of our findings. Since this exploratory study aims at creating a theoretical foundation for a theory testing-oriented stage of research, we present the theoretical development in the form of twenty-nine testable propositions. We conclude by discussing the implications of our findings for the 
design and orientation of the next stage of this research project.

\section{Recent Literature Comparing E-Commerce and E-Government}

As we had found before, the body of comparative literature on e-Commerce and e-Government is very small, if existent at all. So, we had to look at separate streams of literature $[26,35,16]$ to anticipate and isolate potential similarities and differences between eCommerce and e-Government.

On a more general plane, public-to-private differences have been identified in three areas: (1) environmental drivers and constraints, (2) organizational mandates and scope, and (3) internal processes, complexities, and incentives [30]. The private sector has been also praised for its higher agility, greater resourcefulness, less burdensome bureaucracy, and stronger motivation to proactively innovate when compared with public sector organizations $[30,5,25]$.

These differences also surfaced in a study, which compared the strategic priorities of Chief Information Officers (CIOs) in both public and private sectors. It was found that public-sector CIOs focused on (a) the implementation of an IT architecture, (b) cultural change, (d) hiring/retaining skilled professionals, (e) and streamlining business processes, while private-sector CIOs emphasized (a) simplifying business processes, (b) improving services, (c) effective relationships with senior executives, (d) preventing intrusions, and (e) the implementation of IT architecture [36] Process change via streamlining and service improvement were more highly ranked by private-sector CIOs.

Further, the business models of e-Commerce and eGovernment differ in significant ways: while the eCommerce business model aims at creating customer value and at generating revenue, the e-Government business model is based on laws, statutes, and regulations providing citizens and firms with access to government information and services, and also delineating intergovernmental relationships, strategies, and interoperation of electronic government information systems (EGIS) [18], see also [33]. Citizens' acceptance of e-Government rests on trust, information access, public accessibility, quality of service, time saving, efficiency of service, and social awareness [28]. Also, in e-Commerce several sub-models may be found [6], which explain certain differences particularly in process management.

Finally, as our own pilot study uncovered [4], similarities between e-Commerce and e-Government were found regarding (1) process improvements, (2) backend (process) integration, (3) cost savings, (4) information sharing, (5) vertical and horizontal systems integration, (6) increased responsiveness and service quality, (7) standardization efforts, and (8) the criticality of senior leadership support. Differences between the sectors were found to prevail regarding (1) the drivers and motivations for e-Commerce and e-Government, (2) stakeholder expectations, and (3) resource availability (ibid).

\section{Research Question and Methodology}

Study Questions. The two central study questions of this research remained the same as in the pilot:

(1) What is similar in private-sector e-Commerce and public-sector e-Government, and how does it matter?

(2) What is different in private-sector e-Commerce and public-sector e-Government, and how does it matter?

In the absence of any related comparative research antecedents and with a rather thin theoretical foundation relative to the study problem at hand, we decided to continue with our exploratory research approach $[2,8$, 29].

Both e-Commerce and e-Government projects and implementations are engrained in institutional and social settings $[10,27]$ leading to a mesh of socio, technical, and organizational complexities, which defy the reduction of the study problem to a few variables. Under those conditions and accounting for the exploratory nature of the undertaking, we opted for the empirical format of focus group discussions, which has proven highly effective in such study situation $[11,14,15,22,23]$, particularly, since the interaction between participants leads to rich data and high data quality [29].

Sampling Method. The sampling had to be purposive [31], since certain criteria outlined below had to be met in order to qualify for meaningful data. We also stratified the sample using Anthony's framework, which distinguishes between professionals, supervisors with operational control, managers, and strategic planners [1] and chose the managerial level for the pilot, since that level appeared to us high enough for capturing strategic aspects and motives as well as low enough to identify specifics of implementation and outcomes. Individuals were selected on the basis of willingness to participate and on the basis of prior involvement in and experience with e-Commerce or e-Government projects. For both sectors, participants were selected from organizations in the US Pacific Northwest, which has been found highly developed in both e-Commerce (for example, Amazon.com, Boeing, Microsoft, etc.) and e-Government $[17,19,20]$. We required that the projects, in which the participants had been involved, had been of strategic nature to the organization. Also, the project had to contain a major transactional component. In the private-sector focus group we ended up with a total of 18 individuals from leading eCommerce-engaged organizations representing various industries, while we had 17 individuals from the public sector representing the executive branch of various levels of government. A total of six focus groups was conducted with five to six participants each, that is, three groups for each sector.

Data Collection. In the letter of invitation to prospective participants from the private sector, we 
verbally and graphically (see figure 1) introduced the concepts of business-to-consumer (B2C), business-tobusiness (B2B), business-to-government (B2G), businessto-employee (B2E), and internal effectiveness and efficiency (IEE). Likewise, we introduced the concepts of $\mathrm{G} 2 \mathrm{C}, \mathrm{G} 2 \mathrm{~B}, \mathrm{G} 2 \mathrm{G}$, and government-to-employee (G2E) as well as IEE (see also figure 1) in the invitation letters to prospective participants from the public sector. Intentionally, we framed and pre-structured the discussion in that way for systematic comparability. We continue to believe that this framing and pre-structuring would not hamper the expert discussion in any way, on the contrary. For all six groups we introduced the two dimensions of "informational" and "transactional."

\section{E-Government Relationships}
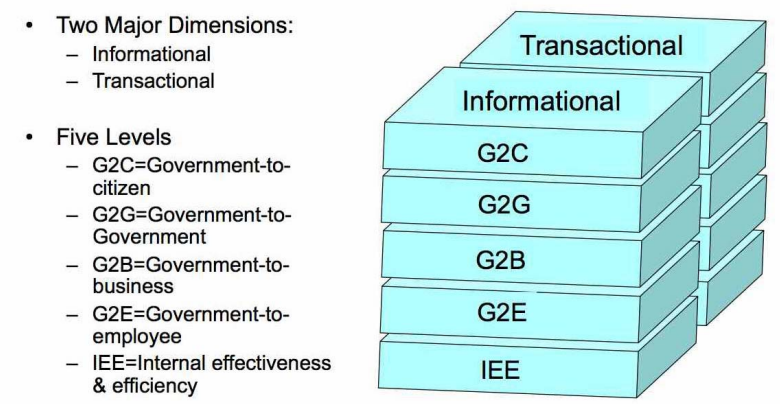

\$.

\section{E-Commerce Relationships}
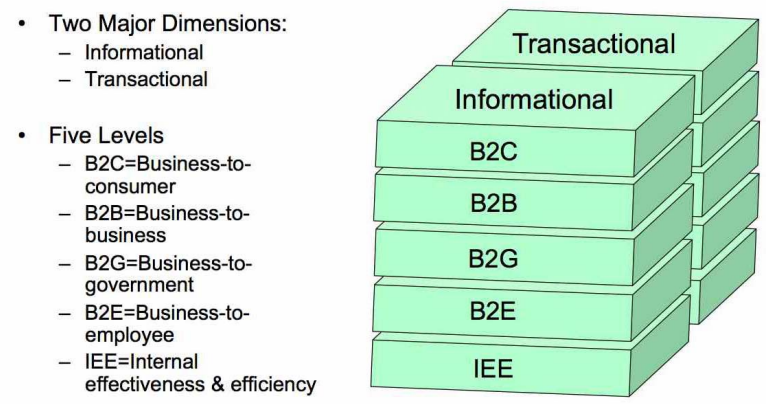

Figure 1 Relationships in e-Government and e-Commerce

The six focus groups were conducted in pairs. They were organized as half-day focus group discussions with the selected participants, first with the private sector participants, the next day with the public sector participants. The moderator first introduced the focus group format to the participants; she then re-introduced the e-Commerce and e-Government concepts as already outlined in the invitation letters. She explained to participants that the first session would be dedicated to the "informational" aspects of the five concepts followed by a second session on the "transactional' aspects. Prior to each session, participants were asked to prepare and write down discussion points for each concept as far as those applied to their projects and experience. The moderator then launched the focus group discussion with an opening question and facilitated the discussion, while three observers took notes and administered the audio recording [22]. The audio tracks were transcribed yielding over 320 pages of transcripts. Also, over 130 pages of notes were taken.

Data Analysis. In this study we mainly used Strauss and Corbin coding methodology [34]. In four passes, the transcripts and emerging concepts were analyzed. First, the four researchers independently read the transcripts identifying units of data. Our impression from the collection exercise was confirmed during this phase that we had in fact managed to collect rich and high-quality data in all four sessions. In the second pass, the two researchers read the transcripts again and consolidated the units of data. In an open coding process [34], each unit of data was then assigned to a preliminary category or subcategory whose dimensions and properties were developed from the data. New categories and subcategories were introduced, in case existing categories did not apply [13]. Convergence and assignment of categories, which the two researchers had identified independently, was performed at each step of the data analysis. In a subsequent pass, an axial coding process was applied, during which the converged categories/clusters and subcategories (emphasized in small capitals below) were analyzed regarding their inherent structures and processes leading to paradigms, whose internal relationships were identified wherever possible [34]. In the final pass, a selective coding process was performed, in which the resulting concepts and theories were related to each other. Surprisingly, the categories/clusters developed for e-Government by and large also emerged for the e-Commerce data analysis allowing for relatively straightforward linkage of the concepts found in the two sectors.

\section{Findings}

In this section, we present our findings for five of a total of eleven main categories or clusters of themes, which we were able to identify from the data. For space limitations, we decided to confine ourselves to presenting findings and analyses for five interconnected clusters. These five clusters, however, we found central to the understanding of similarities and dissimilarities in eCommerce and e-Government. The five clusters comprise (a) process management, (2) information management, (3) citizen/customer focus, (4) stakeholder relations, and (5) the digital divide. For each cluster, we analyze the major elements/themes and their internal and external relations as well as their relative importance, which enables us to develop and present testable propositions, which we will 
use in the next phase of this research project. We highlight the major elements and themes in each category/cluster by using Small Capitals.

\subsection{Process Management}

Process Streamlining and Process Integration

While initial applications would mostly only mimic existing processes electronically ("manumation"), new workflows have been created and processes have been redesigned ("business process <re->design") in more recent projects, which help exploit the new technological capabilities according to the practitioner experts in both eCommerce and e-Government. In both sectors it was said improved internal and external service quality, process speed-ups, and consistent performance of transaction processing were among major driving forces for process redesign and creation of new workflows. Also, the desire to achieve or improve vertical and horizontal process Integration and alignment along with fostering the interoperation between information systems of collaborating institutional partners were among the major drivers for introducing e-Commerce information systems (ECIS) and EGIS. In government, service speed the experts said was still hampered because systems and processes were not aligned well enough. Also, not all transactions could be performed completely electronically due to media breaks or legal requirements. This leads to the following proposition:

Proposition \#01: ECIS and EGIS are more effective when processes are streamlined and new workflows introduced.

Proposition \#02: Organizations in both the public and private sector increasingly engage in redesigning existing processes and create new workflows to make better use of the potential of ECIS and EGIS.

Electronic Transaction Processing as Foundation of Business Strategy

Both ECIS and EGIS provide for high volumes of electronically processed transactions in a cost-effective, speedy, and reliable fashion. With the exception of the highly ECIS/EGIS-enabled procurement process most transactions in government transaction processing were found to be government internal. Transactions involving citizens were still fragmented according to the practitioners. However, compared with government in the private sector, transaction volumes appeared to be much higher. In e-Commerce, transactions were monitored in real time for problem detection, inventory adjustments, and capacity planning. Moreover, historical transactional records were extensively used for market research purposes, pinpointing and profiling highest value customers, brand development, and general strategy development in e-Commerce. Overall, in the data from our sample, electronic transaction processing was found far more sophisticated and far more geared towards directing swift action or reaction in the private sector than in government allowing for high organizational agility in e-Commerce. This leads us to propose,

Proposition \#03: Transaction processing is more sophisticated and proliferated in e-Commerce than in eGovernment.

Proposition \#04: Innovative transaction processing methods are more likely found in e-Commerce than in eGovernment.

Proposition \#05: Historical data from transaction processing are more frequently analyzed and used for strategy development in e-Commerce than in eGovernment.

\section{Alignment and Collaboration}

Experts of both sectors emphasized the increased opportunity for and engagement in institutional COLLABORATION via ECIS and EGIS. In government, inter-agency and inter-municipal (also referred to as government-to-government, or $\mathrm{G} 2 \mathrm{G}$ ) collaboration were found to be motivated through citizen and business demand as well as through expected economies of scale and scope. However, inter-governmental collaboration struggles with the complexity of multiple legal and regulatory processes as well as with different governance structures, agency sizes, and technology sophistication. Creating a supportive culture for collaboration strongly depends on conducive personal relationships between the decision makers of the collaborating entities it was said. Also, according to the practitioners voluntary intergovernmental collaboration was found more effective than imposed collaboration. Partners of similar organizational sizes and governance structure appear to collaborate more easily than partners with different organizational sizes and governance structure. The practitioners declared essential to its success the development of a formal governance structure for the collaboration. Collaboration and alignment were hampered when collaboration partners lacked a shared vision and a common strategy. Finally, formal agreements regarding the governance of collaborative efforts were found essential to the effectiveness and sustainability of a continued collaborative relationship between $G 2 G$ partners.

Proposition \#06: Organizations in both the public and private sector increasingly engage in aligning and integrating processes and workflows to improve collaboration and interoperation.

Proposition \#07: G2G collaboration is more effective between organizations of similar size and similar governance structure than between organizations of dissimilar size and dissimilar governance structure.

Proposition \#08: Governmental organizations that align and integrate business processes for the sake of collaboration also tend to align their strategic priorities.

Proposition \#09: G2G collaboration is more effective on the basis of voluntary participation rather than on the imposition of collaboration. 
In government-to-business (G2B) and business-togovernment (B2G) collaboration the ALIGNMENT OF STRATEGIC PRIORITIES was found essential. Yet, STRUCTURAL PROBLEMS prevented G2B/B2G collaboration in many cases, in part because the government internal process could not always be "digitized," or the difference in transaction speeds in the two sectors. Still, the process and cost improvements were said to be so substantial that the collaboration was justifiable. For that reason, in many G2B/B2G collaborative projects, the private sector partner took on the burden of developing, maintaining, and troubleshooting a collaborative G2B EGIS. Like in G2G collaboration, so in $\mathrm{G} 2 \mathrm{G} / \mathrm{B} 2 \mathrm{G}$ collaboration, formal agreements governing the collaborative effort were found essential to their effectiveness and sustainability.

Proposition \#10: G2G as well as G2B/B2G collaboration is more effective on the basis of formal agreements than without formal agreements that govern the collaborative effort.

Proposition \#11 G2B/B2G collaboration reduces cost, overhead, and transaction completion time for both sides.

\subsection{Information Management}

Information Quality as a Key Factor

In the pilot study INFORMATION QUALITY (IQ) had not surfaced as strongly as an important building block and key factor of information management as it did in the main part of this study. Of the major IQ dimensions of (1) accuracy, (2) comprehensiveness, (3) currency, (4) cognitive authority, (5) assurance/reliability, (6) relevance/precision/recall, (7) timeliness, and (8) perceived value [21], six were mentioned repeatedly in both sectors as key factors of information management and information sharing (accuracy, comprehensiveness, currency, authority, timeliness, and perceived value). Access to information of high quality along those lines was portrayed as crucial to the success of e-projects in both government and commerce. However, with the introduction of EGIS in government as well as ECIS in commerce a tendency towards INFORMATION OVERLOAD has also been detected. In e-Commerce, most information appears to originate from or relate to in-house transactional data sources. Those data were found to be more refined and more ready for mining than in government.

Proposition \#12: The higher the information quality the more effective is information management in both eCommerce and e-Government.

Proposition \#13: Lower information quality affects eCommerce more negatively than e-Government.

Proposition \#14: Maintaining acceptable levels of information quality is more challenging in e-Government than in e-Commerce due to the higher volume of information in government.

\section{Information Sharing}

In government, which appears as more information rich than the private sector, insufficient IQ, non-reliable EGIS, incompatibilities, and lack of information integration it was said frequently still hampered the sharing of information. High accessibility, sufficient performance, and high IQ were identified as major FACILITATORS of information sharing in both sectors. Furthermore, electronically stored information it was said would be and actually is instantly sharable. Many government agencies put much effort into better information integration for the purpose of sharing. Dawes' earlier observation that higher quality information is more readily sought and used [9] we found was strongly supported in the data. The e-Commerce practitioners also mentioned the high value of maintaining historical data on B2B relationships. They also emphasized that ECIS need to be scalable to store, access, and retrieve information at any time and any place. The mining and sharing of huge volumes of transactional data in the private sector the experts reported is tightly monitored and controlled through strict hierarchies of access privileges.

Proposition \#15: In both e-Commerce and eGovernment inter-organizational sharing of information is increasing, leading to more information integration between the partners.

Proposition \#16: The higher the perceived IQ of shared information the more information sharing occurs in both sectors.

Proposition \#17: The more information shared the stronger grows the relationship among partners

\section{Content Management}

Even more than in commerce, website content management was found to pose a major challenge in government. Quite a few participants pointed out that government agencies were lacking a sound STRATEGY for the management of content. The experts referred to the growing complexity of public web content along with government's obligation to make public information publicly and reliably available. Government agencies obviously try to strike a balance between citizens' need for information and the extent of government services to provide that information electronically. Document Life Management, the management of document flows, as well as the proper ARCHIVING of electronic records and removed web content along with previous versions of websites were mentioned repeatedly as major challenges in e-Government content management. Frequently mentioned was also the lack of web content in languages other than English. While web content management in eCommerce was also reported to be a major challenge, it seemingly had a lower degree of complexity and urgency, in part because the legal requirements in this area were far less demanding. In e-Commerce, customer profiles and transactions in progress were enabled to trigger the 
presentation of select content, and content was found to lead into certain types of transactions with certain groups of potential customers. On basis of mining transactional data and maintaining very detailed customer profiles eCommerce organizations it was found had developed a HIGH SOPHISTICATION in fine-grained market and customer targeting. Structured transactional data and nonstructured content was reported to be increasingly joined in ways that sophisticated searches had become possible yielding a plethora of relevant information to identify new marketing opportunities. Also, customer relationship management (CRM) methods had motivated existing customers to keep their profiles updated such that more targeted approaches with pinpoint accuracy could be performed.

Proposition \#18: Content management is more challenging in government than in the private sector due to volume of information and complexity of linked content.

\subsection{Stakeholders Relations}

Additional thematic analysis did not yield additional major concepts than previously reached in pilot. This demonstrates that the cluster is reaching a maturity stage in terms of developing a theory. Three areas needing attention appeared in e-Government: i) governance; ii) collaboration and iii) diversity of stakeholders as opposed to E-Commerce, which mainly emphasized DIVERSITY OF STAKEHOLDERS only.

Governance in E-Government Relations

The governance narrative reflected an ongoing concern in the e-Government side regarding management and CONTROL OF GOVERNANCE STRUCTURE. This appeared particularly important due to a clear border between elected officials and nominated professional staff. While POLITICAL SWINGS may help projects keep going, they may also require more explanations from the professional levels about the rationale of EGIS projects and the ways to measure their effectiveness [32] The importance of governance was also reflected through emphasizing POWER STRUGGLEs among different stakeholders to achieve their particular interests and the fear of stakeholders from losing control.

Proposition \#19: Stakeholders governance structure influences ECIS and EGIS design and deliverables.

Proposition \#20: The process of convincing topleadership to support an EGIS project is harder than in private sector.

Diversity of Stakeholders

This ties up nicely to the next narrative, diversity of stakeholders. To achieve a stable and balanced governance structure one needs to balance relationships among different types of stakeholders, elected and nominated officials, political and professional staff, and federal and local stakeholders. This objective becomes even harder when the boundaries of the system are rigidly fixed for a long period, most of the professional staff retains, the needs are vast and the interests are quite different from each other, pulling into different directions $[12,24]$. For example, participants reported the fear to partner with "a too big city", and to create dependency on their resources and governance structure. Diversity appeared as a critical issue also for the e-Commerce sector due to shaky, temporary and unstable partnership structures. TRANSACTION-DRIVEN PARTNERSHIPS is the main reason for these weak partnership structures. When value of transaction determines the partnership, ad-hoc coalitions appear with different sizes, resources and political power. While partnerships of these sorts help to cover weaknesses of partners, they also make it harder to find a common denominator in shared set of goals. Consequently, this increases the fear of partners, that the partnership can be unbundled at any given moment.

Proposition \#21: The structure of alliances in eCommerce is weaker than the structure of alliances in eGovernment.

Collaboration as a Critical Component of $E$ Government

Finally COLLABORATION and INVOLVEMENT of stakeholders in the process were regarded as of highest importance in the e-Government sector. Collaboration was a necessity of many governmental entities, due to diversity of stakeholders and the need of scaling resources to better serve citizens. For example, while small cities benefited from array of information systems offered to them by bigger cities, bigger cities benefited from such collaborations by providing a better service to citizens, reducing the cost of EGIS and provide a more standardize structure and control of process.

Proposition \#22: Government stakeholders tend to collaborate on mid-to-long terms while stakeholders in the private sector tend to collaborate on short-to-mid terms.

\subsection{Citizen/Customer Focus \\ Citizen/Customer Needs}

Citizen/CUSTOMER NEEDS define much of the way processes and deliverables of technologies are designed both in e-Governement and e-Commerce. Nevertheless, there is a big difference in the way these needs are being regarded and the reason for understanding them. The pilot highlighted the robust process $\mathrm{B} 2 \mathrm{C}$ implements to deliver a product or a service: understand CUSTOMER NEEDS through mechanisms of surveys and TRACKING behavior; gathering this information makes it possible for companies to focus on HIGH VALUE CUSTOMERS and to TARGET SEGMENTS OF CUSTOMERS according to personal characteristics; creating TAILORED BRANDS and services to these particular segments of population; finally, since needs are DYNAMIC, companies have to repeat this process. The main goal of the above illustrated process is to target customers according to their needs and lock them in with the service/product these companies suggest. Needs serve in B2C as an instrumental good since is they 
are valued because they lead to something else, a bottomline result, while for $\mathrm{G} 2 \mathrm{C}$ needs of citizens serve as an intrinsic good, that is they are valued for their own sake. In $\mathrm{G} 2 \mathrm{C}$ needs evolved around the desire and obligation to serve these, for example through providing MORE SERVICE ON THE WEB, and a ONE STOP SHOP, one locus addressing and serving citizens needs. The technology in this case serves as the instrumental value to reach a better level of service to more people and to enhance consistency of content toward a CITIZEN-CENTRIC APPROACH. A concern raised in this context was that citizens are unaware that eGovernment services exist or consider them not to be on a high-level standard like the ones belong to the private sector.

Proposition \#23: In both the private and public sectors designing information systems is highly influenced by customer needs, or citizens' needs respectively.

Proposition \#24: Targeting customers via identifying individuals or groups is more sophisticated and frequent in e-Commerce than targeting citizens in e-Government.

\section{Creating a Strong Customer Experience}

The other side of the coin of revealing the customer needs in B2C is creating these needs through shaping the CUSTOMER EXPERIENCE. While traditionally marketing were the one mainly interested in the customer experience perspective, recently other departments including R\&D joined in shaping and creating this experience. Companies understand that the experience determines much of the transaction or future activities of customers. Experience is a complex concept and companies try to reduce uncertain part from their point of view, the part that they cannot influence in the customer experience. Some aspects might be controllable by the companies, e.g. creating a SOCIAL ENVIRONMENT, enhancing an EASY and CUSTOMIZED online experience, and partially learning how to work with customer EMOTIONS effectively through the technology. There are some aspects that can be analyzed but less transformative, for example the CORE VALUES a customer assigns to an experience. An important note is that this issue was not found and raised in the eGovernment focus groups discussions.

Proposition \#25: Creating and understanding a customer experience is more likely to be found in eCommerce than creating and understanding a citizen experience in e-Government.

Proposition \#26: The higher the enhancement of the social environment of the customer, the more likely it is that the experience will be stronger.

Citizen Participation

Understanding needs and evolving experience is a different matter than involving the customers in the process of developing a product or a service. Involving customers is reported to be prevalent in Web 2.0 applications [7, 37] but according to our findings, which involved other B2C interactions, it was totally ignored.
On the other hand e-Government assigns citizen participation in the process a high weight and importance. Nevertheless, they make sure that the border between participation and control is not blurred. In other words G2C encourages PARTICIPATION in the decision making but not shifting the decision to the citizens.

Proposition \#27: Participation of citizens in G2C processes and in the design of EGIS is higher than participation of customers in B2C and ECIS, respectively.

\subsection{Digital Divide/s}

Similarly to first pilot conducted, we found that the cluster of digital divide was very minor to non-existent in terms of weight it was given by e-Commerce focus group, while it served a big portion of the attention in their counterparts from the e-Government sector. The public sector is well aware to this issue and defines it through levels, first and second levels digital divide/s [3]. The first level of digital divide/s focuses on lack of infrastructure private and public and more generally it deals with ACCESS from a technological point of view. The secondlevel of digital divide/s refers mainly to the usage level. From the users/citizen point of view it includes the lack of SKILLS or AWARENESS as to how to use information, communications technologies effectively and efficiently. From the government point of view it focuses on how to make content ACCESSIBLE (e.g., content that would be accessible by people with disabilities). This includes a big challenge of accessibility from a LANGUAGE perspective that is not yet implemented. The pilot manifested that eGovernment is more focused on the second-level of digital divide/s, that is more on the content, than the traditional one.

E-Commerce marginalizes and neglects the concept of digital divide/s. It is of less importance to this sector since the drivers are transactions. For example, localization of content will occur if a market exists and there is a demand from consumers. The concept itself implies a certain criterion of social responsibility, which contemporarily many companies like to brag about. This pilot demonstrates that words are nice but they are not applied necessarily in the interactions of companies and consumers. It emphasized differences in justifications to the existence of e-commerce vs. e-Government entities: business and economic sustainability vs. service and executing policy. Digital divide/s is a 'nice to have' concept to e-Commerce and is a top-priority challenge to e-Government.

Proposition \#28: Addressing the challenges of the digital divide/s is more likely to be found in eGovernment than in e-Commerce.

Proposition \#29: Addressing second-level digital divide/s takes more attention in EGIS projects than firstlevel digital divide/s.

\subsection{Discussion and Summary}

We set out to investigate, identify, and characterize the similarities and differences between e-Commerce and 
e-Government since we believed that the findings from such a study would benefit academic knowledge and eCommerce and e-Government practice alike. In the following we discuss and summarize our observations and insights.

Similarities between e-Commerce and e-Government (research question \#1)

According to our findings both ECIS and EGIS benefit their respective organizations significantly more when the underlying workflows and processes are not only electronic re-embodiments of their paper-based antecedents but rather streamlined, simplified, or completely discarded and replaced by different workflows and processes, which take full advantage of the technology. This seems to be increasingly understood in both commerce and government. We also found completely new workflows in both sectors, which would not have been possible without ECIS and EGIS.

A great incentive for streamlining and redesigning workflows and processes we found in the increased degree of collaboration within and between the sectors, which has become possible in an instantaneous fashion through ECIS and EGIS.

We further found that collaboration between partners within and across sectors works better when it unfolds on the basis of formal agreements. In government, it was noted that imposed collaboration works poorly as opposed to collaborative engagements based on freedom of choice.

Interestingly, cross-sector collaboration based on ECIS/EGIS reduces cost and speeds up the process on both ends even if the private-sector partner provides systems, infrastructure, and maintenance.

Along with transactional collaboration and integration we found increasing collaboration within and across sectors also in the area of information sharing. If collaboration thrives, we saw even the partial alignment of strategic objectives as a result. Information quality played a critical role in this context. A positive feedback between perceived IQ, information sharing, and the strength of the relationship seemed to exist.

We found in both sectors that similar governance structures of organizations influenced how collaborative ECIS and EGIS were designed. Remarkably, in both sectors the perceived needs of citizens (and customers, respectively) strongly influenced the designs of respective sytems. In e-Commerce, organizations were interested in providing a social environment, which was conducive to a positive experience as a customer.

These findings suggest that ECIS/EGIS-related phenomena have important characteristics in common, which go beyond the mere technical resemblance of systems and methods. Process redesign practices might be a worthwhile subject of further study. Likewise, practices and principles of organizational and technical collaboration appear to provide valuable experiences to be shared.

\section{Differences between e-Commerce and e-Government (research question \#2) \\ However, we also found formidable differences in} practices, principles, and drivers between e-Commerce and e-Government.

Transaction processing was found more sophisticated and of far higher volume in commerce than in government. On the other hand, information processing and management, including the archiving of electronic records we found much more developed in the public sector than with private firms. The drivers of innovation were stronger in e-Commerce than in a e-Government; however, the overall sophistication of EGIS did not appear to lag behind ECIS by orders of magnitude. Yet, private sector firms were found to make far more elaborate use of historical data and data in processing in order to optimize desired organizational outcomes than government agencies. Lower information quality was also found to lead to more immediate and economically more negative effects in e-Commerce than in e-Government. Still, governments struggled more than commercial organizations to maintain acceptable levels of information quality leading to far greater challenges, for example, in content management.

Interestingly, leadership in government appeared to be more supportive of (in particular, collaborative) eprojects than their commercial counterparts. It also appeared that collaborative structures in the public sector were markedly stronger than those in the private sector.

Although many EGIS initiatives seemingly greatly cared about citizens' involvement and participation, we found that private firms had an edge in creating a "customer experience." Almost in contradiction to this finding, we noticed that citizens were far more influential in the design of EGIS than customers were in the design of ECIS. At this point, we refrain from speculative explanations for the lack of a sufficiently large base of data.

Overall, what we found different between eCommerce and e-Government suggests that the two phenomena follow different trajectories despite many similarities and technical commonalities. One obvious explanation lies in the sector-specific differences, which produce different drivers also in this area. It will be interesting to analyze to what extent Enterprise Resource Planning (ERP) systems, which are increasingly introduced in government, may help align the trajectories between e-Commerce and e-Government to a higher degree than we found in this study.

Surprise Findings

The process of involving diverse participants and the rich data that evolved from the focus groups illuminated few important phenomena, which need to be discussed.

One strident finding is the absence of discussion or reference to the issue of ethics both in the e-Government and e-Commerce focus groups. A whole array of clusters 
emerging from the discussions (e.g., information management and digital divide) dealing with people did not raise any challenges or concerns related to normative decisions of right and wrong. The prevalence of information technologies and usage involves many questions of ethics. Managers gathering and analyzing personal and sensitive information on customers, government officials deciding to implement information systems according to political constraints, and accuracy and level of information quality provided to customers and citizens are few examples of the inter-linkage between ethics and e-Government and e-Commerce. Striping decisions and strategy from a system of values and norms may be more easy and beneficial in the short horizon, but in the long run may cause inherent difficulties in managing e-government or e-commerce initiatives.

Another problematic phenomenon we found is the disregard of issues of digital divide/s by the private sector. The public sector makes many efforts to understand and address needs of diverse groups in society. EGIS hels the public sector to reach growing portions of the population more efficiently and effectively, through for example providing information in different languages or making information more accessible to populations with disabilities. The private sector, on the other hand, may address indirectly issues of digital divide/s, including issues of access and usage, but only if economic profitability is attached to these needs. Digital divide/s was not raised in the private sector as a concept, because it is not addressed directly, but as a by-product of other initiatives.

\section{Limitations and future research}

In our samples of participants from the two sectors we found after the focus groups were conducted that eGovernment experts on average were from higher levels in the organizational hierarchy than e-Commerce practitioners who were more technically oriented and versed. Our results, hence, may be skewed that they represent more strategic perspectives in e-Government and more operational/tactical perspectives in eCommerce.

We also recognize that what we present here is the result of an exploratory study based on a limited number of participants. Our study attempts to lay theoretical foundations for more quantitatively oriented research on the subject, which will lead us to more generalizable results. We plan to use the twenty-nine propositions developed here in a successive study aimed at closing that gap.

\section{Acknowledgement}

We are indebted to our two graduate students Tim Carlson from the Master of Science in Information Management (MSIM) program, Deborah Turner from the doctoral program who helped us prepare for and conduct this research.

\section{References}

[1] R. N. Anthony, Planning and Control Systems; a Framework for Analysis. Boston: Division of Research, Graduate School of Business Administration, Harvard University, 1965.

[2] S. Arthur and J. Nazroo, "Designing Fieldwork Strategies and Materials," in Qualitative Research Practice: A Guide for Social Science Students and Researchers, J. Ritchie and J. Lewis, Eds. London; Thousand Oaks, Calif.: Sage Publications, 2003, pp. 109-137.

[3] K. Barzilai-Nahon, "Gaps and Bits: Conceptualizing Measurements for Digital Divide/S," The Information Society, vol. 22, pp. 10, 2006.

[4] K. Barzilai-Nahon and H. J. Scholl, "Similarities and Differences of e-Commerce and e-Government: Insights from a Pilot Study," in 40th Hawaii International Conference on System Sciences (HICSS40), R. Sprague, Ed. Waikoloa/Big Island, HI: IEEE, 2007, pp. 92c(1-10).

[5] B. Bozeman, " Exploring the Limits of Public and Private Sectors: Sector Boundaries as Maginot Line.," Public Administration Review, vol. 48, pp. 672-674, 1988.

[6] Y.-P. Chang and J. Yan, "Positioning in a New Dynamic ECommerce Business Model," in 3rd International Conference on Wireless Communications, Networking and Mobile Computing (WICOM 2007). Shanghai, PR China: IEEE, 2007, pp. 3592 - 3595.

[7] E. Constantinides and S. J. Fountain, "Web 2.0: Conceptual Foundations and Marketing Issues," Journal of Direct, Data and Digital Marketing Practice, vol. 9, pp. 231-244, 2008.

[8] J. W. Creswell, Educational Research: Planning, Conducting, and Evaluating Quantitative and Qualitative Research, 2nd ed. Upper Saddle River, N.J.: Merrill, 2005.

[9] S. S. Dawes, "Interagency Information Sharing: Expected Benefits, Manageable Risks," Journal of Policy Analysis and Management, vol. 15, pp. 377-394, 1996.

[10] G. DeSanctis and M. S. Poole, "Capturing the Complexity in Advanced Technology Use: Adaptive Structuration Theory," Organization Science, vol. 5, pp. 121-147, 1994.

[11] H. Finch and J. Lewis, "Focus Groups," in Qualitative Research Practice: A Guide for Social Science Students and Researchers, J. Ritchie and J. Lewis, Eds. London; Thousand Oaks, Calif.: Sage Publications, 2003, pp. 170198.

[12] L. S. Flak and S. Nordheim, "Stakeholders, Contradictions and Salience: An Empirical Study of a Norwegian G2g Effort," in Proceedings of the 39th Annual Hawaii International Conference on System Sciences, (HICSS39 eGovernment Track), vol. 4. Kauai: IEEE, 2006, pp. 75a75 tig.

[13] G. E. Gorman, P. Clayton, M. L. Rice-Lively, and L. Gorman, Qualitative Research for the Information Professional: A Practical Handbook. London: Library Association Publishing, 1997.

[14] T. L. Greenbaum, The Handbook for Focus Group Research, 2nd ed. Thousand Oaks, Calif:: Sage Publications, 1998. 
[15] T. L. Greenbaum, Moderating Focus Groups: A Practical Guide for Group Facilitation. Thousand Oaks, Calif.: Sage Publications, 2000.

[16] A. Groenlund, "State of the Art in e-Gov Research: Surveying Conference Publications," International Journal of Electronic Government Research, vol. 1, pp. 1-25, 2005.

[17] A. T.-k. Ho, "Reinventing Local Governments and the EGovernment Initiative," Public Administration Review, vol. 62, pp. 434-444, 2002.

[18] M. Janssen, G. Kuk, and R. W. Wagenaar, "A Survey of Web-Based Business Models for E-Government in the Netherlands," Government Information Quarterly, vol. 25, pp. 202, 2008.

[19] C. Kaylor, R. Deshazo, and D. Van Eck, "Gauging EGovernment: A Report on Implementing Services among American Cities," Government Information Quarterly, vol. 18, pp. 293-307, 2002.

[20] C. H. Kaylor, "The Next Wave of e-Government: The Challenges of Data Architecture," Bulletin of the American Society for Information Science and Technology, vol. 31, pp. 18-22, 2005.

[21] R. Klischewski and H. J. Scholl, "Information Quality as the Capstone of E-Government Integration, Interoperation, and Information Sharing," Electronic Government, an International Journal, vol. 5, pp. 203-285, 2008.

[22] R. A. Krueger and M. A. Casey, Focus Groups: A Practical Guide for Applied Research, 3rd ed. Thousand Oaks, Calif:: Sage Publications, 2000.

[23] E. Madriz, "Focus Groups in Feminist Research," in Handbook of Qualitative Research, N. K. Denzin and Y. S. Lincoln, Eds., 2nd ed. Thousand Oaks, Calif.: Sage Publications, 2000, pp. 835-850.

[24] A. Mathie and J. C. Greene, "Stakeholder Participation in Evaluation: How Important Is Diversity?" Evaluation and Program Planning, vol. 20, pp. 279-285, 1997.

[25] L. Mohan and W. K. Holstein, "Eis: It Can Work in the Public Sector," MIS Quarterly, vol. 14, pp. 434-448, 1990.

[26] E. W. T. Ngai and F. K. T. Wat, "A Literature Review and Classificatiuon of Electronic Commerce Research," Information \& Management, vol. 39, pp. 415-429, 2002.

[27] W. J. Orlikowski and D. Robey, "Information Technology and the Structuring of Organizations," Information Systems Research, vol. 2, pp. 143-169, 1991.

[28] R. Park, "Measuring Factors That Influence the Success of E-Government Initiatives," in 41st Hawaii International Conference on System Sciences (HICSS41). Waikoloa, HI: IEEE, 2008, pp. 218 - 218.

[29] M. Q. Patton, Qualitative Research and Evaluation Methods, 3 ed. Thousand Oaks, Calif.: Sage Publications, 2002.

[30] H. Rainey, R. Backoff, and C. Levine, "Comparing Public and Private Organizations," Public Administration Review, vol. 36, pp. 233-244, 1976.

[31] J. Ritchie, J. Lewis, and E. Gillian, "Designing and Selecting Samples," in Qualitative Research Practice: A Guide for Social Science Students and Researchers, J.
Ritchie and J. Lewis, Eds. London; Thousand Oaks, Calif: Sage Publications, 2003, pp. 77-108.

[32] K. A. Schildt, S. Beaumaster, and S. Bailey, "Organization Antecedents of Successful It Management," presented at Proceedings of the 39th Annual Hawaii International Conference on System Sciences (HICSS'06) - EGovernment Track, Kauai, 2006.

[33] B. C. Stahl, "The Paradigm of E-Commerce in EGovernment and E-Democracy," in Electronic Government Strategies and Implementation, W. Huang, K. Siau, and K. K. Wei, Eds. Hershey PA: Idea Group Pub., 2005, pp. 1-19.

[34] A. L. Strauss and J. M. Corbin, Basics of Qualitative Research: Techniques and Procedures for Developing Grounded Theory, 2nd ed. Thousand Oaks: Sage Publications, 1998.

[35] Y. Wang, J. Li, P. Liu, and F. Yang, "Electronic Commerce Research Review: Classification and Analysis," in 3rd International Conference on Wireless Communications, Networking and Mobile Computing, (WiCom 2007). Shanghai, PR China: IEEE, 2007, pp. 3505 - 3508.

[36] M. Ward and S. Mitchell, "A Comparison of the Strategic Priorities of Public and Private Sector Information Resource Executives," Government Information Quarterly, vol. 21, pp. 284-304, 2004.

[37] M. Zajicek, "Web 2.0: Hype or Happiness?" presented at Proceedings of the 2007 international cross-disciplinary conference on Web accessibility (W4A), Banff, Canada, 2007. 